\title{
Effectiveness of the mechanical excitation applied to the olive paste: possible improving of the oil yield, in malaxation phase, by vibration systems
}

\author{
Tullia Gallina Toschi, ${ }^{1,2}$ Annachiara Berardinelli, ${ }^{2}$ Chiara Cevoli, ${ }^{1}$ Eleonora laccheri, ${ }^{1}$ \\ Giuseppe Di Lecce, ${ }^{1}$ Alessandra Bendini, ${ }^{1,2}$ Luigi Ragni ${ }^{1,2}$ \\ ${ }^{1}$ Department of Agricultural and Food Sciences, University of Bologna; ${ }^{2}$ Inter-Departmental Centre \\ for Agri-Food Industrial Research, University of Bologna, Cesena (FC), Italy
}

\begin{abstract}
The mechanical vibrations characterized by a frequency lower than $200 \mathrm{~Hz}$ could promote the cells breakage and improve the oil extraction process by avoiding, at the same time, the negative effects on the commercial qualitative parameters due to the use of the heating during malaxation. Vibration tests were conducted by means of an electrodynamic shaker in order to find the optimal frequency levels of excitation, able to put in a resonant condition the olive paste. Sinusoidal accelerations at constant acceleration $\left(120 \mathrm{~m} / \mathrm{s}^{2}\right)$, in a range between 5 and $200 \mathrm{~Hz}$ were explored. The $50 \mathrm{~Hz}$ and $80 \mathrm{~Hz}$ frequencies were able to put in resonant condition the olive paste. In the vibrated samples at $50 \mathrm{~Hz}$ (15 min of treatment), the maximum increment of the extraction efficiency (about 53\% in comparison with the control), was observed. Further studies could be conducted in order to assess the synergic effect of the mechanical vibrations and the malaxation on the oil extraction efficiency, with the aim of reducing the time of the whole phase and avoiding changes in the oil quality traits.
\end{abstract}

Correspondence: Alessandra Bendini, Department of Agricultural and Food Sciences (DISTAL), Alma Mater Studiorum - University of Bologna, piazza Goidanich 60, 47521 Cesena (FC), Italy.

Tel. +39.0547338121 - Fax: +39.0547382348 .

E-mail: alessandra.bendini@unibo.it

Key words: olive oil, malaxation, mechanical vibration, olive paste, oil yield.

Funding: the research was carried out with the financial contribution of the Italian Ministry of the Instruction, University and Research in the framework of the PRIN 2009 project Innovative technologic applications to improve the extraction yield of virgin oils from olives and seeds and for rapid controls of their quality.

Received for publication: 11 December 2013.

Accepted for publication: 22 January 2014

(C) Copyright T. Gallina Toschi et al., 2013

Licensee PAGEPress, Italy

Journal of Agricultural Engineering 2013; XLIV:225

doi:10.4081/jae.2013.225

This article is distributed under the terms of the Creative Commons Attribution Noncommercial License (by-nc 3.0) which permits any noncommercial use, distribution, and reproduction in any medium, provided the original author(s) and source are credited.

\section{Introduction}

The olive oil extraction process can be divided into three main phases: the olives crushing, the olives paste malaxation and the olive oil separation from water (Uceda et al., 2006).

In the first phase, the olive fruits are broken with the aim of liberate the oil drops contained in mesocarp cells. The olive paste, obtained after the olive crushing, has then to be malaxed to achieve the emulsion breaking, the merging of small droplets of oil into larger drops, and the formation of a continuous liquid phase.

This mechanical process, that will facilitates the subsequent separation step, is considered a key phase of the extraction process for virgin olive oil both in terms of oil extraction yield increasing and preservation of commercial qualitative parameters. During malaxation, chemical and enzymatic reactions take place; these activities can markedly modify the composition of the oil, especially if an excessive heating accompanies the process (Boselli et al., 2009; Clodoveo, 2012).

The formation of the liquid phase can be in fact improved by increasing the temperature of the paste during the malaxation step. The consequent decrease of the paste viscosity helps the formation of the oil continuous phase and raises the oil extraction yield (Inarejos-García et al., 2009). However, it is well known that the malaxation, if severe, can have a negative effect on the oil quality in terms of phenols content and volatile components and in terms of acceleration of oxidative processes (Angerosa et al., 2001; Ranalli et al., 2001).

A great quantity of literature was dedicated to the effect of the time and temperature of the malaxation treatments on the virgin olive oil extraction yield and quality. These works were extensively reviewed by Clodoveo (2012) together with a critical analysis concerning the use of a particular atmosphere composition and coadiuvants (water, salt, hydrated magnesium silicate and calcium carbonate to name a few) during the process. For what concerns the temperature, according to Angerosa et al. (2001), an appreciable oil extraction yield can be measured when levels are not higher that $30^{\circ} \mathrm{C}$. Passing from $30^{\circ} \mathrm{C}$ to $35^{\circ} \mathrm{C}$, processes responsible of the formation of primary and secondary oxidation products can have an increment together with the activity of the lipase enzymes.

Recentlly, some relative new technologies have been proposed in order to improve the olive oil extraction process by reducing the malaxation process length. These technologies, used in many food applications, are based on ultrasounds (Jiménez et al., 2007; Clodoveo and Hbaieb, 2013) and microwaves (Clodoveo and Hbaieb, 2013).

By using ultrasounds (frequency higher than $16 \mathrm{kHz}$ ), two differ- 
ent effects occur in the extraction: one thermal, due to the absorption of the ultrasonic energy from the olive paste and one mechanical that provides cell breaking due to the cavitation effect. By using microwaves (from $300 \mathrm{MHz}$ to $300 \mathrm{GHz}$ ), the electromagnetic energy is converted in thermal energy with a final result of the rupture of the cell and the consequent spillage of its content.

Since the application of the cited innovative technologies in the virgin oil extraction process is recent and few studies were dedicated to these topics, many aspects of the application should be cleared, especially the potential negative effects on the oil commercial qualitative parameters.

In order to improve the extraction process and reduce the malaxation length, also the use of the mechanical vibrations (under $200 \mathrm{~Hz}$ ) during olive oil extraction could be interesting in the olive oil technological panorama. The vibration applied in the resonant conditions of the olive paste as pre-treatment and in combination with the traditional malaxator can have a positive effect in terms of extraction efficiency and oil quality. The mechanical vibrations can allow the breaking of the cells and facilitate the next operations without relevant and critical thermal effects.

The present study aims to assess the effectiveness of the mechanical vibrations applied to the olive paste to improve oil yield. Sinusoidal vibration tests will be conducted in the $5-200 \mathrm{~Hz}$ frequency range on olive paste after hammer crushing. Comparisons with a vertical malaxator in terms of extraction efficiencies were conducted.

\section{Materials and methods}

\section{Olive fruit samples}

Correggiolo variety (Olea europaea L.) olive samples were collected in October/November 2011 in the area near Rimini (Northern Italy, Emilia-Romagna region, Italy). Olive maturation index (Jaen index) was assessed according to the International Olive Oil Council method (Uceda and Hermoso, 1998), by measuring the average colouring of olive fruits (peel and pulp). The maturation index of the olives of employed varied between 3.59 and 3.70 .

Theoretical performance, in term of total oil content of fresh olive samples, was calculated by using the method proposed by Uceda and Frias (1975), giving the value, in weight percentage, of 14.5 \pm 1.5 .

\section{Oil extraction system}

Oil was extracted by using a continuous low-scale plant with a maximum process capacity about $1.5 \mathrm{q} / \mathrm{h}$ (Oliomio 150, Tavernelle Val di Pesa, Florence, Italy), equipped with eight hammer crushers, a vertical malaxator composed by 14 blades grouped in two pair (one constituted by six elements and the other one by eight elements) and a two-phase decanter (Figure 1). The rotation speed of the hammer crush and the malaxer were about $2000 \mathrm{rpm} / \mathrm{min}$ and $30 \mathrm{rpm} / \mathrm{min}$, respectively. For the experimentation $60 \mathrm{~kg}$ of olives were treated for each cycle (3 cycles in total). For each test, a portion of olive paste was collected after crushing and used for the vibration tests; another one was used as control sample and the remained paste was malaxed for about $35 \mathrm{~min}$. The layout of the experimental procedure is shown in Figure 2.

\section{Vibration tests}

Vibration tests were conducted by means of an electro-dynamic shaker (S202; Unholtz-Dickie Corp., Wallingford, CT, USA) at Food Science campus (Cesena, Italy). The shaker was driven by an electronic power amplifier (MA240; Unholtz-Dickie Corp.) and operated by a control console (DP 350 Win; Data Physics Corp., San Jose, CA, USA). A steel cylinder ( $97 \mathrm{~mm}$ in diameter $\times 200 \mathrm{~mm}$ in height) was fixed on the vibrating table to contain the olive paste during the tests (about $1000 \mathrm{~g}$ for each test). Preliminary tests were carried out in order to identify the optimal frequency levels of the excitation, able to put in a resonant condition the olive paste. To this aim, sinusoidal accelerations at constant acceleration $\left(120 \mathrm{~m} / \mathrm{s}^{2}\right)$ and at frequency linearly increasing with the time $(1.62 \mathrm{~Hz} / \mathrm{s})$, in the $5-200 \mathrm{~Hz}$ range, were used to excite the paste.

During these preliminary tests, the mechanical behaviour of the paste was assessed by means of a piezoelectric accelerometer (4393 V; Brüel \& Kjær, Nærum, Denmark) placed inside the cylinder previously filled with the sample and connected to a charge amplifier (Nexus 2692; Brüel \& Kjær) (Figure 3). The acceleration signals

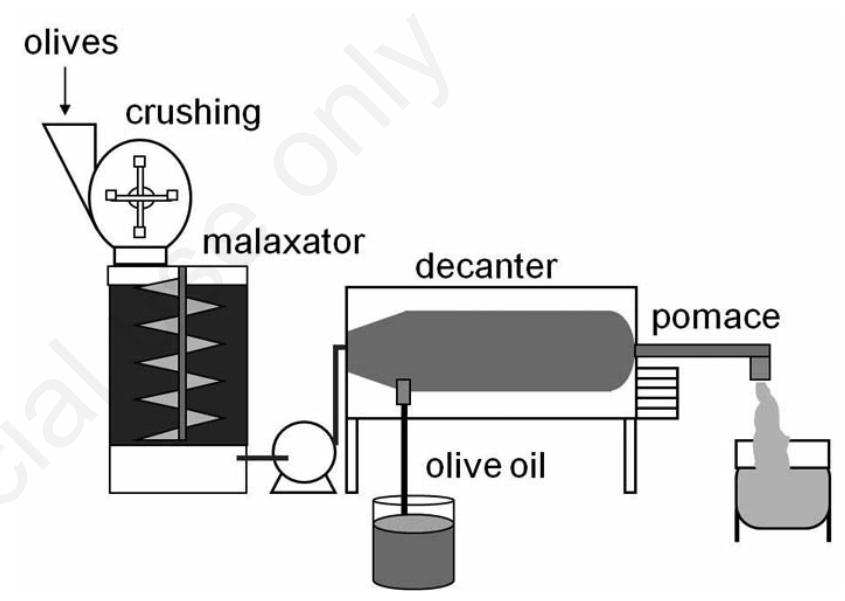

Figure 1. Diagram of the continuous low-scale plan used for olive oil extraction.

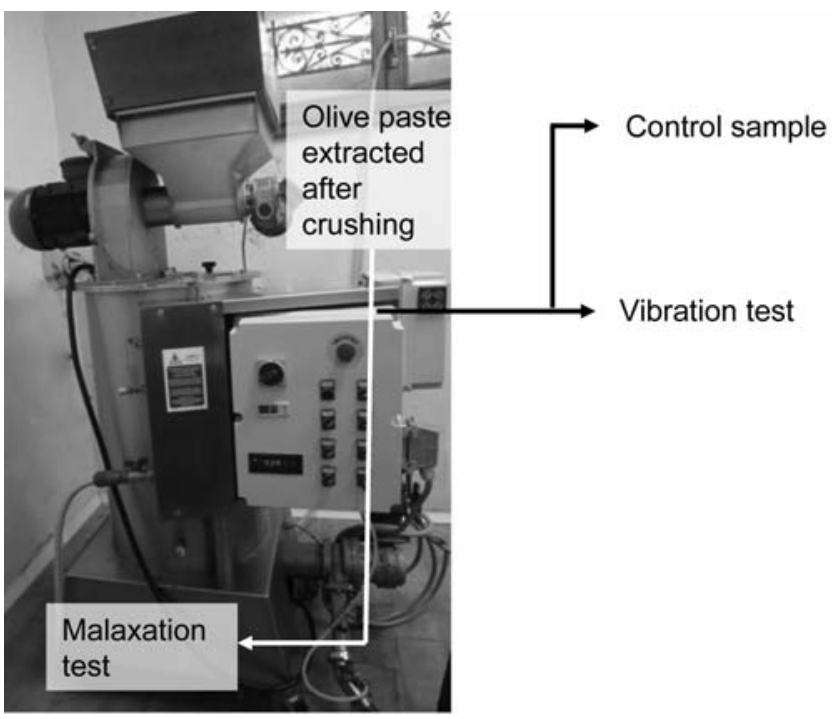

Figure 2. Layout of the experimental procedure. 
were acquired and analysed by means of an acquisition board (PCI $6024 \mathrm{E}$; National Instruments, Austin, TX, USA) and a programme written in Labview version 5.1 (National Instruments). The acquired signals were processed via fast Fourier transform algorithm.

The temperature of the paste can increase by increasing the excitation time (within the same level of the acceleration and frequency) and it is well known that the quality of the extracted oil can be affected by an increase in the temperature (Uceda et al., 2006). For this reason, after the identification of the most convenient frequency levels, two different test durations were carried on. The test durations were defined by carrying out further preliminary tests characterized by sinusoidal accelerations at constant accelerations $\left(120 \mathrm{~m} / \mathrm{s}^{2}\right)$ at the selected frequency levels, but with different durations (from 5 to $55 \mathrm{~min}$, increments of $10 \mathrm{~min})$.

\section{Assessment of the oil extraction efficiency}

The extraction efficiency was assessed in terms of grams of oil obtained by centrifugation of $25 \mathrm{~g}$ of olive paste into a $50 \mathrm{~mL}$ test tube (BD FALCONTTM ${ }^{\mathrm{TM}}$, San Jose, CA, USA) (3500 rpm $\left.\times 5 \mathrm{~min}\right)$. These assessments were conducted on the pastes excited by using the electro-dynamic shaker and on the malaxed and on the control pastes. For each sample, five replications were performed.

Immediately after the centrifugation, the liquid phases (oil and water) were poured into another $50 \mathrm{~mL}$ test tube, with the aid of a strainer (BD FALCONT ${ }^{\mathrm{TM}}$ ) and centrifuged again $(3500 \mathrm{rpm} \times 3 \mathrm{~min})$. The paste surface was washed using $10 \mathrm{~mL}$ of $n$-hexane. The oil dissolved in $n$-hexane was then transferred in a flask, dried and weighed. During the tests, control samples were stored at about $20-22^{\circ} \mathrm{C}$ for the same time required for vibration and malaxation tests.

Statistical differences $(\mathrm{P}<0.05)$ between the vibrated, the malaxed and the control samples were found, in terms of percentage of oil extracted from the olive paste, by using the Student's $t$-test (SPSS 13.0 for Windows; IBM SPSS Statistics, Armonk, NY, USA).

\section{Results and discussion}

\section{Vibration tests}

Figure 4 shows the olive paste accelerations $\left(\mathrm{m} / \mathrm{s}^{2}\right)$ analysed in the frequency domain and measured by means of a piezoelectric accelerometer placed inside the sample.

Two acceleration peaks at $527 \mathrm{~m} / \mathrm{s}^{2}$ and at $464 \mathrm{~m} / \mathrm{s}^{2}$ can be respectively observed at $50 \mathrm{~Hz}$ and $80 \mathrm{~Hz}$. At these two frequencies, the initial acceleration of $120 \mathrm{~m} / \mathrm{s}^{2}$ was amplified of about four times and the olive paste reached the resonant condition, which was also visually appreciated. At these frequencies the paste clearly appeared released from the
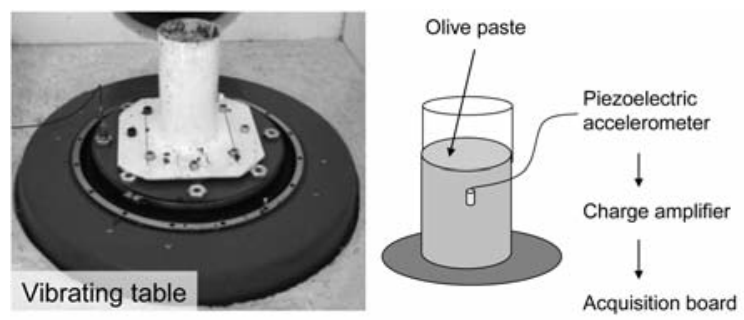

Figure 3. The vibrating table and a detail of the piezoelectric accelerometer placed inside the olive paste during the experimental tests. system (steel cylinder) and characterized by a whirling motion. Since the $50 \mathrm{~Hz}$ frequency showed to produce the highest resonant acceleration of the olive paste, the extraction efficiency was assessed by using these following three vibration treatments: $50 \mathrm{~Hz}$ at two durations (5 and $15 \mathrm{~min}$ ) and $80 \mathrm{~Hz}$ for $15 \mathrm{~min}$. At these conditions (frequency and duration of the vibration) a maximum increase of about $2{ }^{\circ} \mathrm{C}$ was measured in the temperature of the olive paste, being the temperature of the olive paste before the vibrations about $20^{\circ} \mathrm{C}$.

In order to assess if the extraction efficiency is related to a specific resonant frequency of the paste or if a narrow range of frequencies can be used, also in consideration of a possible resonant frequency shift due to the different characteristics of the olives, a further vibration treatment was conducted at frequency linearly increasing with the time $\left(1.22 \times 10^{-2} \mathrm{~Hz} \mathrm{~s}^{-1}\right)$ in the $45-55 \mathrm{~Hz}$ range, for $15 \mathrm{~min}\left(120 \mathrm{~m} / \mathrm{s}^{2}\right)$.

\section{Assessment of the oil extraction efficiency}

The results in terms of percentage of extracted oil from olive pastes, submitted to the different vibration treatments, and to the malaxation process are shown in Figure 5 together with the relative controls.

According to Figure 5, both the vibration at constant frequency and

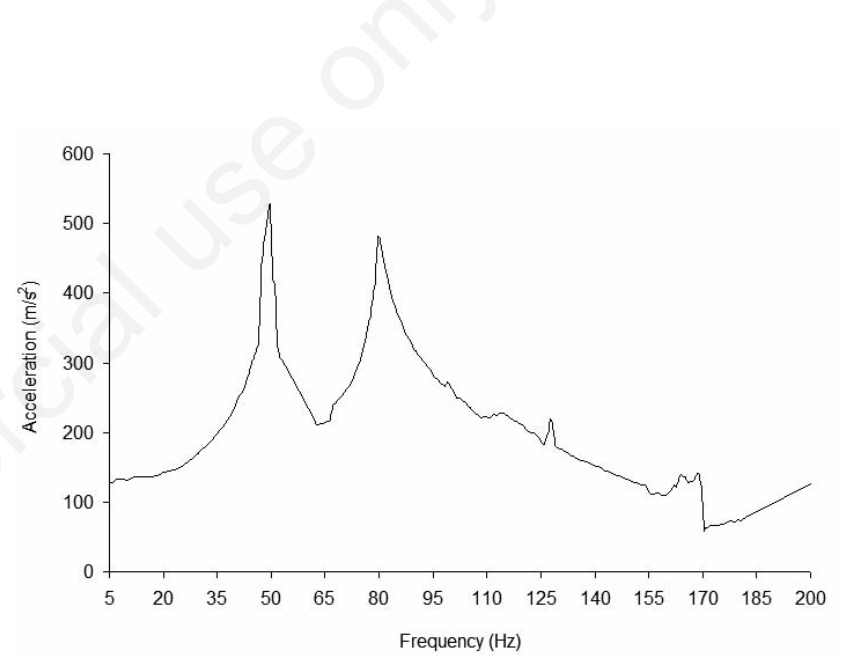

Figure 4. Acceleration $\left(\mathrm{m} / \mathrm{s}^{2}\right)$ in the frequency domain, measured by the accelerometer placed in the olive paste submitted to a sinusoidal accelerations $\left(120 \mathrm{~m} / \mathrm{s}^{2}\right)$.

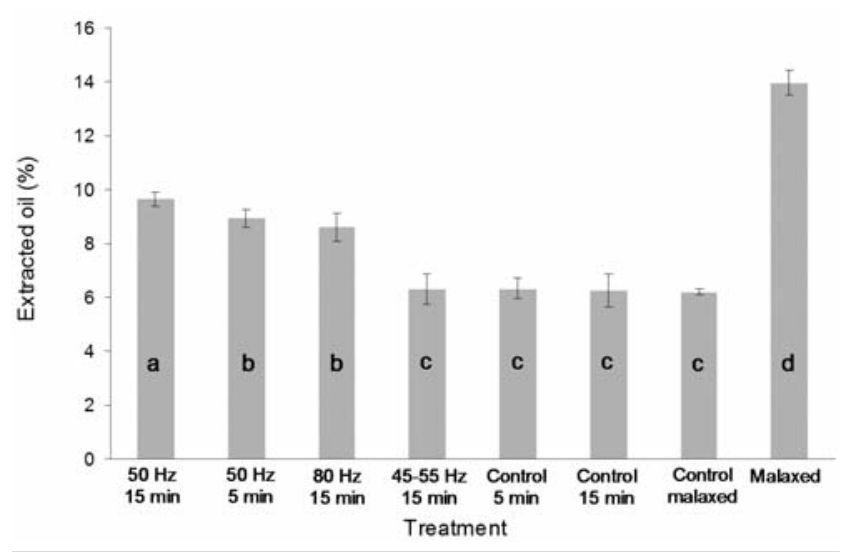

Figure 5. Mean values of the oil extraction efficiency (\%) for the vibrated, the malaxed and the control samples. Vertical bars are standard deviations; differences between means with the same letter are not significant at at $\mathrm{P}<0.05$. 
the malaxed process appeared to significantly improve the oil extraction (\%) respect to the control paste.

The highest extraction (more than the double respect to the relative control sample) was observed for the malaxation process. Since the malaxation involves a greater mechanical stress respect to the mechanical vibrations, this result is not surprising.

For the vibrated samples, the highest percentage of extraction was obtained for the olive paste submitted, for $15 \mathrm{~min}$ at $50 \mathrm{~Hz}$ vibration (about 53\% of increment respect to the relative control sample). Both the frequency and the duration of the vibration significantly affected the extraction efficiency. Even if slight, significant differences were found between the two tested frequencies $50 \mathrm{~Hz}$ and $80 \mathrm{~Hz}$ (within the same vibration duration of $15 \mathrm{~min}$ ) and between the two considered durations 5 and $15 \mathrm{~min}$ (at $50 \mathrm{~Hz}$ ).

The treatment conducted by vibrating the paste with a sweep in the frequency range $45-55 \mathrm{~Hz}$ for 15 min did not show a significant increment in terms of capacity to release oil in comparison with the control sample.

The olive paste submitted to the sweep, even if vibrated in a range containing the value of $50 \mathrm{~Hz}$, showed a significant different behaviour respect to the samples vibrated at the single frequency $50 \mathrm{~Hz}$. Unobserved improvement in the extraction efficiency in the $45-55 \mathrm{~Hz}$ vibrated olive paste can be due to the necessity of conducting and maintaining a vibration exactly at the resonant conditions frequency, for the right time. No significant difference emerged between the three control samples ( 5 and 15 min of vibration, and the malaxed).

\section{Conclusions}

A significant increase in the extraction yield was observed in the vibrated olive pastes. Both resonant excitation frequency and duration can significantly affect the oil extraction. Respect to a control sample, a maximum increment of about $53 \%$ of the extraction efficiency was observed at $50 \mathrm{~Hz}$ and after $15 \mathrm{~min}$ of treatment. After the vibration tests, a maximum increase of $2^{\circ} \mathrm{C}$ of the temperature paste was measured. The resonant conditions experimentally founded were surely related to the physical-mechanical characteristics of the tested olive pastes and can be affected by several factors such as the cultivar, the maturity stage of the olives and the milling process. What emerged with certainty is that the extractive effectiveness occurred at a precise frequency and, in this sense, it will be necessary to set, from time to time and in relation with the geometry and dimension of a possible real plant, the frequency of excitation more favourable for maximum extraction of the oil.

Compared to the malaxation process, the extraction efficiency of the vibrated oil pastes showed a significantly lower extraction power. This is not surprising because the two methods, the vibration and the malaxation, involve a different mechanical stress to the paste.

Further studies can be carried out in order to assess if the combination of the vibration with the malaxation can positively influence the quality of the virgin oil produced and the energy balance of the process, by reducing the time of the whole malaxation phase.

\section{References}

Angerosa F., Mostallino R., Basti C., Vito R. 2001. Influence of malaxation temperature and time on the quality of virgin olive oils. Food Chem 72:19-28.

Boselli E., Di Lecce G., Strabbioli R., Pieralisi G., Frega N.G. 2009. Are virgin olive oils obtained below $27^{\circ} \mathrm{C}$ better than those produced at higher temperatures?. Food Sci. Technol. 42:748-57.

Clodoveo M.L. 2012. Malaxation: Influence on virgin olive oil quality. Past, present and future - an overview. Trends Food Sci. Tech. 25:13-23.

Clodoveo M.L., Hbaieb H. 2013. Beyond the traditional virgin olive oil extraction systems: Searching innovative and sustainable plant engineering solutions. Food Res. Int. 71:57-62.

Inarejos-García A., Gómez-Rico A., Salvador M.D., Fregapane G. 2009. Influence of malaxation conditions on virgin olive oil yield, overall quality and composition. Eur. Food Res. Technol. 228:671-7.

Jiménez A., Beltran G., Uceda M. 2007. High-power Ultrasound in olive paste pretreatment. Effect on process yield and virgin olive oil characteristics. Ultrason. Sonochem. 14:725-31.

Ranalli A., Contento S., Schiavone C., Simone N.2001. Malaxing temperature affects volatile and phenol composition as well as other analytical features of virgin olive oil. Eur. J. Lipid Sci. Tech. 103: 228-38.

Uceda M., Frias L. 1975. Trend of the quality and quantitative composition of olive fruit oil during ripening. pp 25-46 in Proc. Int. Meeting on Olive Oil, Cordoba, Spain.

Uceda M., Hermoso M. 1998. La calidad del aceite de oliva. In: D. Barranco, R. Fernàndez-Escobar, L. Rallo, (eds.) El cultivo del olivo. Junta de Andalucía Ediciones Mundi-Prensa, Spain, pp 547-72.

Uceda M., Jimenez A., Beltran G. 2006. Olive oil extraction and quality. Grasas Aceites 57:25-31. 